\title{
Diagnostics of emission condition of compression ignition engine in utilization of tested substance
}

\author{
Ján Polerecký ${ }^{1}$, Juraj Jablonický ${ }^{2}{ }^{*}$, Juraj Tulík ${ }^{2}$, Ján Kosiba ${ }^{2}$, Marcin Zastempowski ${ }^{3}$, and \\ Mirko Simikić ${ }^{4}$ \\ ${ }^{1}$ S-EKA spol. s r.o., authorized organization for emission control of road vehicles, Kupecká 5, 94901 \\ Nitra, Slovak Republic \\ ${ }^{2}$ Faculty of Engineering, Slovak University of Agriculture in Nitra, Tr. A. Hlinku 2, 94976 Nitra, \\ Slovak Republic \\ ${ }^{3}$ Faculty of Mechanical Engineering, UTP University of Science and Technology in Bydgoszcz, al. \\ Prof. S. Kaliskiego 7, 85-796 Bydgoszcz, Poland \\ ${ }^{4}$ Faculty of Agriculture, University of Novi Sad, Trg. Dositeja Obradovića, 21101 Novi Sad, Serbia
}

\begin{abstract}
This paper focuses on the observation of a decrease in smoke opacity values in application of tested substance in selected vehicles with a compression ignition engine. The aim of the paper is to evaluate the ability of the tested substance to decrease the smoke opacity value in vehicles equipped with the compression ignition engine with mileage above 30,000 $\mathrm{km}$. Measurements were carried out on the basis of determined measurement methods. From the results obtained in measurements on two vehicles, it can be concluded that the utilization of the tested substance led to a decrease in the smoke opacity value in both observed vehicles. The results of the experiment show further possibility for decreasing of emission production in exhaust gases of motor vehicles equipped with the compression ignition engine.
\end{abstract}

\section{Introduction}

Developments in the field of technology bring with their positive impact and increase of life quality also undesirable side effects. One of the severe adverse effects of the scientific and technical progress is environmental pollution $[1,2,3,4,5,6]$. The transport sector has a significant influence on worsening ecological situation as it not only particulates in ecosystem pollution but is also one of the main causes for the existence of global energy issues. We can now witness the producers' efforts to increase the ecological safety taking place as early as in the motor vehicle development. As a result, vehicles are equipped with exhaust systems supplemented with exhaust gas treatment equipment. Engine developers and producers can also utilize alternative fuels (CNG, LPG, E85, biodiesel) as an energy source for vehicles, as well as transition to hybrid propulsion (combustion and electric motor) and introduction of fuel cells. Another option for increasing of ecological safety is an application of electric drives. In evaluating the ecological impact of vehicle operation, it is necessary to take into account all the factors participating in environmental load, from production of the vehicle, its drive units and accessories up to disposal of the vehicle.

With regard to the need for limiting air pollution by combustion engine exhaust gases, the maximum production of pollutants in exhaust gas emissions of all motor vehicles is legally limited. The EU legislature sets the maximum permissible values of exhaust gas emissions (EURO limits) during the type tests for general authorization to operate (homologation) and during the pollutant emission checks (emission checks) of vehicles in

\footnotetext{
*Corresponding author: juraj.jablonicky@uniag.sk
} 
operation. Emission limits are expressed in terms of engine performance and validity period, given in $\mathrm{g} . \mathrm{kW}^{-1} \cdot \mathrm{h}^{-1}$. Limited are $\mathrm{CO}$, hydrocarbons, volatile organic $\mathrm{HC}$ compounds, suspended $\mathrm{PM}$, and $\mathrm{NO}_{\mathrm{x}}$ oxides. With growing strictness of the limits, the sulfur content in diesel fuel has been decreasing over the years. The lowering of sulfur content is relevant from the standpoint of the technologies utilized for further emission treatment, such as solid particulate filters, in which sulfur reduces the efficiency of performance and lifespan [7]. Engine emissions contain hundreds of chemicals with different concentrations, the biological properties (impact on human health) of which have not been exactly determined to date. In case additives are used in fuel, applied directly to the working area of the combustion engine, new types of substances, usually not present in exhaust gases, can be generated, further contributing to the catalytic chemical reactions. These are for example some of the fuel additives - "fuel-borne catalysts", used to support the regeneration of particulate filters and connected to the production of highly toxic dioxin and furan emissions [8]. The possibility of new substance generation needs to be taken into account also when additives (e.g. catalytic) are applied to fuel or lubricating oils and when liquids are added to exhaust gases. A common example is urea used for reduction of $\mathrm{NO}_{\mathrm{x}}$ emissions in SCR (Selective Catalytic Reduction) catalysts - in such a case SCR may contain ammoniac and multiple other substances from incomplete decomposition of urea. Combustion engines are responsible for more than $70 \%$ of global $\mathrm{CO}$ emissions production and $19 \%$ of global $\mathrm{CO}_{2}$ emissions production. In addition to the products of perfect combustion - i.e. $\mathrm{CO}_{2}, \mathrm{H}_{2} \mathrm{O}$, excess oxygen, excess nitrogen - which represent the majority of exhaust products, a wide range of other gases and solids may occur, which tend to hold greater attention: CO, non-combusted hydrocarbons (paraffins, olefins, aromatic hydrocarbons), partially combusted hydrocarbon (aldehydes and ketones), degradation products (acetylene, ethylene, hydrogen, soot), nitrogen oxides $\mathrm{NO}_{\mathrm{x}}$ ( $\mathrm{NO}$ - nitrogen monoxide, $\mathrm{N}_{2} \mathrm{O}$ - dinitrogen monoxide, $\mathrm{NO}_{2}$ - nitrogen dioxide) and solid particulate matter. The degree of harmfulness of individual exhaustion gas elements is sometimes given by means of comparison to the harmfulness of $\mathrm{CO}$. Providing objective figures for levels of harmfulness is certainly difficult. It is evident from the operation of a compression ignition engine that the increase in smoke opacity leads to an increase in production of pollutants (CO and $\mathrm{HC}$ ), the measuring of which is difficult in practice, however. It is therefore vital for practice to observe the value of particulate emissions PM (Particulate Matter), the measuring of which is much faster and technologically and economically simple, while simultaneously being sufficient for evaluation of technical condition. Compression ignition engines operate narrowly below the smoke opacity threshold during the maximum performance [9]. Engine operation results in production of smoke, generated due to insufficient oxygenation of the fuel in the combustion cycle, i.e. due to insufficient combustion. Smoke production is thus caused either by lack of airflow or excess of fuel. Both causes are invariably bound with the technical condition of the compression ignition engine.

One of the ways to comply with the stricter emission regulations is to focus on and search for suitable alternative fuels. The main plausible alternative fuels used in car transport are ethanol, hydrogen and biodiesel [10]. Hydrogen-based fuel cells could become a real alternative to fossil fuels, but for this to be commercially viable, many technical issues need to be solved beforehand, such as intricacy of hydrogen production, requirements for the infrastructure for its storage and high production costs of the fuel cell. A high number of studies have shown that biodiesel could serve as an alternative for compression ignition engines, with small or even no requirements for their adjusting [11]. It was also proven that biodiesel has a great potential for decreasing the $\mathrm{CO}_{2}, \mathrm{CO}$, THC (Total Hydro Carbon) emissions and PM emissions Regulation no. 24 [12, 13]. In conclusion, alternative fuels and their mixtures with diesel fuel are still a subject of research, focusing 
primarily on reduction of emission production arising from their combustion in engine, but also on the transformation of their heat into mechanical energy.

\section{Measurement of solid particles emission}

The method of measurement of solid particle emissions by opacity observation is based on the principle of measuring the physical property of a gaseous environment characterizing the optical absorbability of a gas column of a defined length - i.e. opacity, which is expressed by the value of attenuation coefficient. Opacity, measured by means of an opacimeter, is therefore an inverted value of transparency. The value of opacity (smoke opacity) is expressed by light attenuation coefficient $k$, the determining of which is laid down by UN/ECE Regulation [12] in accordance with UN/ECE Regulation [14, 15] and is calculated by means of Eq. (1):

$$
\phi=\phi_{O} \cdot e^{-k L}
$$

where: $L$ - effective length of the light path in the observed gas, m; $\Phi_{O}-$ light flux emitted from the observed gas, -; $\Phi$ - incident light flux, -; $k$ - light attenuation coefficient, $\mathrm{m}^{-1} ; e-$ base of natural logarithm.

It can be observed from Eq. 1 that the attenuation coefficient $k$ (Eq. 2) is a logarithmic function of the ratic

$$
k=-\frac{1}{L} \frac{\log \frac{\Phi}{\Phi_{0}}}{\log e}, m^{-1}
$$

Opacity measurement by the method of free acceleration is defined by Law no. 106/ 2018 for the measurement of particulate emissions used to control the emission condition of the diesel engine, as well as for homologation tests of road motor vehicles [16]. Measurement conditions are laid down by Annex IV of Council-Directive 2014/45/EU.

\subsection{Equipment used in measurements}

In measurements of the emission condition of vehicles while utilizing the tested substance, the following measuring devices were used:

1. Speed measurement device DiSpeed 492 by AVL, registered at Graz, which is intended to be used for measuring of engine speed of both two- and four-stroke engines. Speed scanning is based on measurement of signal caused by engine vibrations or of sound vibrations scanned by a sensor applied to the engine of the controlled vehicle by means of a permanent magnet.

2. MAHA MGT 5 and MDO - 2 Lon Euro emission tester by MAHA Maschinenbau Haldenwang GmbH \& Co. KG Germany, which meets the requirements set by UN/ECE Regulation no. 24 and ISO 11614:1999 [12, 17](Reciprocating internal combustion compression-ignition engines - Apparatus for measurement of the opacity and for determination of the light absorption coefficient of exhaust gas).

\subsubsection{Measurement method}

1. Carry out first measurements for obtaining of input values of smoke opacity and for evaluation of emission condition of the vehicles without the tested substance.

2. Repeat measurement of vehicle emission condition without the tested substance after $1,000 \mathrm{~km}$ (permissible deviation $+200 \mathrm{~km}$ ).

3. Determine the minimal required number of measurements by means of mathematical statistical analysis from the obtained input values.

4. Determine the dosage ratio.

5. Carry out the vehicle emission condition measurements with the tested additive substance - after $500 \mathrm{~km}$ (permissible deviation $+100 \mathrm{~km}$ ).

6. Carry out every subsequent measurement with the tested substance after additional 600 $\mathrm{km}$ (permissible deviation $\pm 100 \mathrm{~km}$ ). 
7. Evaluation of the results obtained.

\subsubsection{Mathematical statistical analysis}

Determining the necessary number of experiment repetitions can be, according to the listed methods, carried out when the standard deviation of the observed property or variation coefficient are known. These values can be known from previous measurements, from preliminary control measurements or literature. If the standard deviation is known, it is possible to determine the necessary number of experiment repetitions for selection with repetition on the basis of Eq. 3:

$$
n=t_{a}^{2} \cdot \frac{s}{\Delta^{2}}
$$

where: $n$ - the number of repetitions being determined; $t_{a}$ - the critical value of normal distribution for bilateral estimate; $\Delta$ - the selected value of the required accuracy; $s$ - the estimate of the standard deviation of the core set.

In determining the necessary number of repetitions of the selection set, Eq. 4 provided by [18] can be used:

where: $N-$ the size of the set used.

$$
n=\frac{N \cdot t_{a}^{2} \cdot s^{2}}{t_{a}^{2} \cdot s^{2}+N \cdot \Delta}
$$

If the variation coefficient of the set $V_{k}$ is known, then the necessary number of repetitions can be det

$$
n=\frac{v_{k}^{2} \cdot t_{a}^{2}}{\delta^{2}}
$$

where: $n$ - the observed number of repetitions; $t_{a}$ - critical value of normal distribution for bilateral estimate; $v_{k}$ - variation coefficient, $\% ; \delta$ - maximum permissible error, $\%$.

\subsection{Characteristic of the tested substance}

The tested substance is designed for additivation of diesel fuel of all types according to EN 590. The ferrocene active substance influences the combustion process and in perfect combustion lowers the exhaust gas emissions. The tested substance decarbonizes the combustion engine and maintains the cleanliness of the fuel system. It decarbonizes the area of the first piston ring and nozzle outlet. After decarbonization, the combustion chamber becomes covered by a brightly red microscopic protective layer and does not produce any harmful compounds.

\subsubsection{Criteria for evaluation of influence of the tested substance}

The following criteria were set for evaluation of the influence of the tested substance on the emission parameters of the vehicles:

1. The mileage of the test vehicles must be at least $30,000 \mathrm{~km}$.

2. The vehicles must be fully operational in road traffic.

Table 1 contains the basic characteristics of the observed vehicles to which the substance for emission lowering was applied.

Table 1. Characteristics of the tested vehicles.

\begin{tabular}{|l|c|c|}
\hline \multicolumn{1}{|c|}{ Mark } & Vehicle 1 & Vehicle 2 \\
\hline Cylinder capacity & $2,287.2 \mathrm{~cm}^{3}$ & $2,999.0 \mathrm{~cm}^{3}$ \\
\hline Catalytic converter & KAT & KAT \\
\hline Maximum engine power/engine speed & $88.00 \mathrm{~kW} / 3,600 \mathrm{~min}^{-1}$ & $115.50 \mathrm{~kW} / 3,500 \mathrm{~min}^{-1}$ \\
\hline Fuel type/energy source & diesel & diesel \\
\hline
\end{tabular}




\begin{tabular}{|c|c|c|}
\hline Transmission/number of gears & MT6 & MT6 \\
\hline Operating weight & $2,060 \mathrm{~kg}$ & $2,215 \mathrm{~kg}$ \\
\hline Maximum permissible total weight & $3,500 \mathrm{~kg}$ & $3,500 \mathrm{~kg}$ \\
\hline \multicolumn{3}{|c|}{ Emissions and consumption } \\
\hline Emissions EC/UNECE & $\begin{array}{c}\text { 70/220*2003/76B } \\
\text { (EURO 4) }\end{array}$ & $\begin{array}{c}\text { 70/220*2003/76B } \\
\text { (EURO 4) }\end{array}$ \\
\hline SMOKE OPACITY EC/UNECE & $72 / 306 * 2005 / 21$ & $72 / 306 * 2005 / 21$ \\
\hline $\mathrm{CO}$ & 0.091 g.km ${ }^{-1}$ & 0.069 g.km ${ }^{-1}$ \\
\hline $\mathrm{NO}_{\mathrm{x}}$ & 0.352 g.km ${ }^{-1}$ & 0.350 g.km ${ }^{-1}$ \\
\hline $\mathrm{HC}+\mathrm{NO}_{\mathrm{x}}$ & 0.396 g.km ${ }^{-1}$ & $0.362 \mathrm{~g} \cdot \mathrm{km}^{-1}$ \\
\hline Particles & 0.053 g.km ${ }^{-1}$ & 0.056 g.km ${ }^{-1}$ \\
\hline Corrected attenuation coefficient & $0.970 \mathrm{~m}^{-1}$ & $1.540 \mathrm{~m}^{-1}$ \\
\hline $\mathrm{CO}_{2}$ & 220 g. km ${ }^{-1}$ & 246 g.km ${ }^{-1}$ \\
\hline
\end{tabular}

\section{Results and discussions}

For the objective assessment of the tested substance from the perspective of smoke opacity value reduction, it was necessary to determine the minimum sufficient number of experiment repetitions by means of mathematical and statistical analysis. Input data for the determination of the number of repetitions were obtained from smoke opacity measurements on the sample of vehicles equipped with a compression ignition engine with mileage over $30,000 \mathrm{~km}$.

From the experience gained during the measurements and continuous evaluation of the measured data, the number of test repetitions was determined on the basis of variation coefficient, according to Eq. 5. The calculation is based on the maximum permissible error $\delta=10 \%$ and critical value $t_{a}=1.64$ determined with a probability of $90 \%$, which is considered sufficient in experiments within machine engineering (Regulation no. 49). The calculated value $n=67$ represents the minimum number of necessary test repetitions.

Vehicle no. 1, the essential parameters of which are shown in Table 1, has the maximum smoke opacity of $1.47 \mathrm{~m}^{-1}$ according to the regulations provided by the manufacturer. It was necessary to maintain the range of idling and maximum engine speed specified by the vehicle's manufacturer during testing. Before the application of tested sample to vehicle's fuel system, initial measurements were performed in order to assess the technical condition of the compression ignition engine of the tested vehicle. As evident from Table 2, the combustion engine in vehicle no. 1 is in adequate technical condition; this is indicated by the mean smoke opacity value determined after two measurement cycles realized after a $1,100 \mathrm{~km}$ run. The mean smoke opacity value was $0.46 \mathrm{~m}^{-1}$, i.e. $68.9 \%$ less than required by legislature. 
Table 2. Measured input values of smoke opacity for vehicle no. 1.

\begin{tabular}{|c|c|c|c|c|c|c|c|c|c|c|c|}
\hline \multicolumn{12}{|c|}{ Vehicle no. 1} \\
\hline \multirow{5}{*}{\multicolumn{3}{|c|}{$\begin{array}{l}\text { Obligatory data for } \\
\text { testing }\end{array}$}} & \multicolumn{4}{|c|}{ Engine temperature, ${ }^{\circ} \mathrm{C}$} & \multicolumn{5}{|c|}{80} \\
\hline & & & \multicolumn{4}{|c|}{ Idling engine speed, $\min ^{-1}$} & \multicolumn{5}{|c|}{ from 500 to 1,000} \\
\hline & & & \multirow{2}{*}{\multicolumn{4}{|c|}{$\begin{array}{l}\text { Maximum engine speed, } \text { min }^{-1} \\
\text { Smoke opacity-permissible, } \\
\mathrm{m}^{-1}\end{array}$}} & \multicolumn{5}{|c|}{ from 3,500 to 5,500} \\
\hline & & & & & & & \multicolumn{5}{|c|}{1.47} \\
\hline & & & \multicolumn{4}{|c|}{ Dispersion, $\mathrm{m}^{-1}$} & \multicolumn{5}{|c|}{0.5} \\
\hline 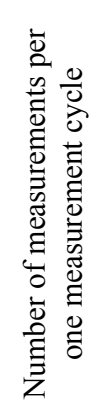 & 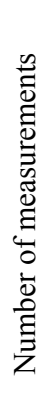 & 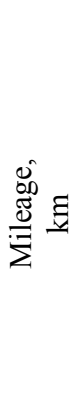 & 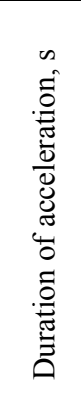 & 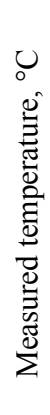 & 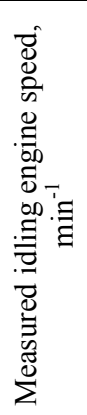 & 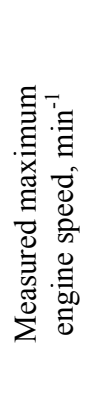 & 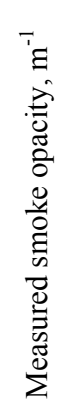 & 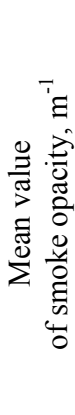 & 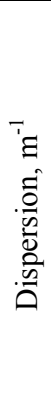 & 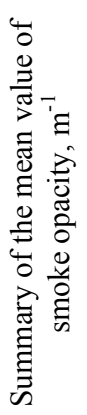 & 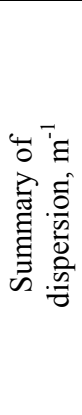 \\
\hline \multicolumn{12}{|c|}{ Measurement without the tested substance } \\
\hline \multirow{3}{*}{1} & 1 & \multirow{3}{*}{\begin{tabular}{l}
$\infty$ \\
\multirow{0}{0}{} \\
$\stackrel{\infty}{\infty}$
\end{tabular}} & 1.55 & & 810 & 4,330 & 0.53 & ก & ¿ & \multirow{5}{*}{$\stackrel{0}{\circ}$} & \multirow{5}{*}{$\stackrel{9}{\circ}$} \\
\hline & 2 & & 1.35 & 83 & 800 & 4,370 & 0.49 & $\dot{0}$ & $0^{\circ}$ & & \\
\hline & 3 & & 1.42 & & 810 & 4,410 & 0.53 & S & $\mathrm{S}$ & & \\
\hline \multirow{3}{*}{2} & 4 & \multirow{3}{*}{$\underset{\infty}{\stackrel{\infty}{ \pm}}$} & 1.41 & & 800 & 4,430 & 0.46 & \multirow{2}{*}{ ஓ̊. } & \multirow{2}{*}{$\stackrel{1}{\div}$} & & \\
\hline & 5 & & 1.48 & 81 & 800 & 4,370 & 0.39 & & & & \\
\hline & 6 & & 1.45 & & 800 & 4,470 & 0.34 & $\mathrm{~S}$ & $\mathrm{~S}$ & $\mathrm{~S}$ & $\mathrm{~S}$ \\
\hline
\end{tabular}

S - satisfactory

After testing the compression ignition engine technical condition in vehicle no. 1, the tested substance was applied to the fuel system in a mixing ratio of $29.5 \mathrm{ml}$ of tested substance per 60 liters of fuel. According to the obtained results, the test itself can be divided into three phases. In the first phase, the mean smoke opacity value before decarbonization was 0.42 $\mathrm{m}^{-1}$. The mileage of vehicle no. 1 was $1,110 \mathrm{~km}$ at this point of testing. The second phase is represented by the process of decarbonization; it is characterized by an increase in smoke opacity value due to cleaning of the combustion chamber. The mean smoke opacity value was $0.86 \mathrm{~m}^{-1}$; the mileage of vehicle no. 1 was $3,010 \mathrm{~km}$ in the second phase. The third phase includes the monitoring of the tested vehicle in operation after decarbonization. The mean smoke opacity value in this phase was $0.33 \mathrm{~m}^{-1}$ with a mileage of $9,790 \mathrm{~km}$. The graphical dependence of all three phases of the smoke opacity value monitoring with utilization of the tested substance in tested vehicle no. 1 is shown in Fig. 1.

If only the first and third phases were included in the final assessment of the tested substance's impacts on smoke opacity, then the mean smoke opacity value of vehicle no. 1 would be $0.37 \mathrm{~m}^{-1}$, representing a decrease in smoke opacity by $74.5 \%$ in comparison with the value specified by the manufacturer. When comparing the sums of mean smoke opacity values from the first and third phase with the smoke opacity value measured before 
application of the tested substance, a $17.9 \%$ decrease in the smoke opacity value can be observed.

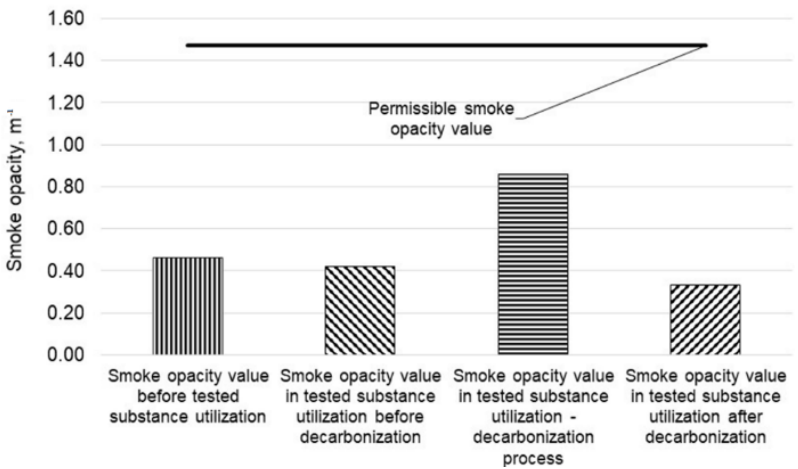

Fig 1. Graphical dependence of individual smoke opacity monitoring phases using the test sample in observed vehicle no. 1 .

Vehicle no. 2, the essential parameters of which are shown in Table 1, has the maximum smoke opacity of $2.04 \mathrm{~m}^{-1}$ according to the regulations provided by the manufacturer. It was necessary to maintain the range of idling and maximum engine speed specified by the vehicle's manufacturer during testing. Before application of the tested sample to vehicle's fuel system, initial measurements were performed in order to assess the technical condition of the compression ignition engine of the tested vehicle. As evident from Table 3, the combustion engine of vehicle no. 2 is in adequate technical condition. This is confirmed by the mean smoke opacity value determined after two measuring cycles realized after a 1,150 $\mathrm{km}$ run. The mean smoke opacity value was $2.04 \mathrm{~m}^{-1}$, i.e. $49.18 \%$ less than required by legislature.

Table 3. Measured input values of smoke opacity for vehicle no. 2.

\begin{tabular}{|c|c|c|c|c|c|c|c|c|c|c|c|}
\hline \multicolumn{12}{|c|}{ Vehicle no. 2} \\
\hline \multirow{5}{*}{\multicolumn{3}{|c|}{$\begin{array}{l}\text { Obligatory data for } \\
\text { testing }\end{array}$}} & \multicolumn{4}{|c|}{ Engine temperature, ${ }^{\circ} \mathrm{C}$} & \multicolumn{5}{|c|}{80} \\
\hline & & & \multicolumn{4}{|c|}{ Idling engine speed, $\min ^{-1}$} & \multicolumn{5}{|c|}{ from 500 to 1,000} \\
\hline & & & \multicolumn{4}{|c|}{ Maximum engine speed, $\min ^{-1}$} & \multicolumn{5}{|c|}{ from 3,500 to 4,550} \\
\hline & & & \multicolumn{4}{|c|}{ Smoke opacity - permissible, $\mathrm{m}^{-1}$} & \multicolumn{5}{|c|}{2.04} \\
\hline & & & \multicolumn{4}{|c|}{ Dispersion, $\mathrm{m}^{-1}$} & \multicolumn{5}{|c|}{0.5} \\
\hline 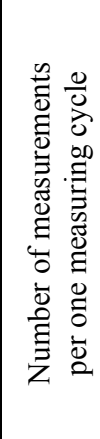 & 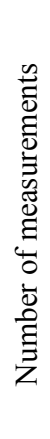 & 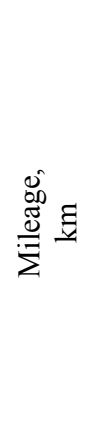 & 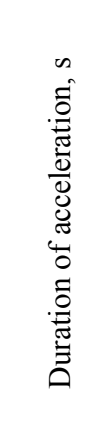 & 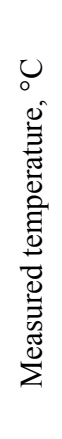 & 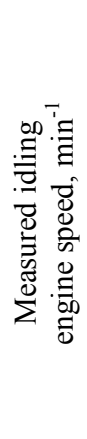 & 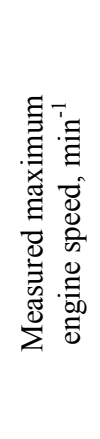 & 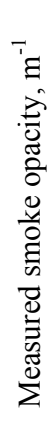 & 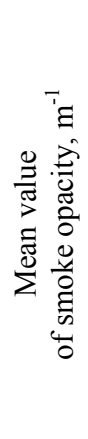 & 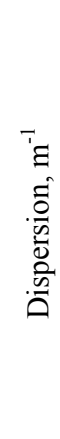 & 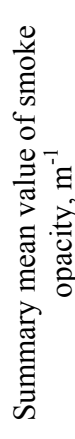 & 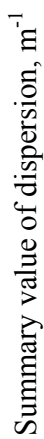 \\
\hline
\end{tabular}




\begin{tabular}{|c|c|c|c|c|c|c|c|c|c|c|c|}
\hline \multicolumn{12}{|c|}{ Measurement without the tested substance } \\
\hline \multirow{3}{*}{1} & 1 & \multirow{3}{*}{$\begin{array}{l}8 \\
\text { Oे } \\
\text { m }\end{array}$} & 1.21 & & 810 & 4,100 & 1.09 & & & \multirow{5}{*}{$\underset{-}{0}$} & \multirow{5}{*}{ 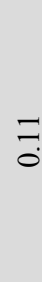 } \\
\hline & 2 & & 1.30 & 80 & 810 & 4,110 & 1.05 & & & & \\
\hline & 3 & & 1.21 & & 810 & 4,110 & 1.09 & $\mathrm{~S}$ & $\mathrm{~S}$ & & \\
\hline \multirow{3}{*}{2} & 4 & \multirow{3}{*}{$\begin{array}{l}\stackrel{i}{n} \\
\stackrel{5}{m}\end{array}$} & 1.08 & \multirow{3}{*}{81} & 800 & 3,604 & 0.98 & \multirow{2}{*}{1.00} & \multirow{2}{*}{0.03} & & \\
\hline & 5 & & 1.00 & & 799 & 4,200 & 1.00 & & & & \\
\hline & 6 & & 1.02 & & 800 & 4,200 & 1.01 & $\mathrm{~S}$ & $\mathrm{~S}$ & $\mathrm{~S}$ & $\mathrm{~S}$ \\
\hline
\end{tabular}

$\mathrm{S}$ - satisfactory

After testing of the compression ignition engine technical condition in vehicle no. 2, the test substance was, similarly to the previous case, applied to the fuel system in a mixing ratio of $29.5 \mathrm{ml}$ of test substance per 60 liters of fuel. According to the results obtained, the test itself can be divided into three phases. In the first phase, the mean smoke opacity value before decarbonization was $0.92 \mathrm{~m}^{-1}$. The mileage of vehicle no. 2 was $540 \mathrm{~km}$ at this point of testing. The second phase is represented by the process of decarbonization; it is characteristic by an increase in smoke opacity value due to cleaning of the combustion chamber. The mean smoke opacity value was $1.15 \mathrm{~m}^{-1}$; the mileage of vehicle no. 2 was $1,840 \mathrm{~km}$ in the second phase. The third phase represents the monitoring of vehicle's operation after decarbonization. The mean smoke opacity value in the third phase was 0.95 $\mathrm{m}^{-1}$; the mileage of vehicle no. 2 was $10,380 \mathrm{~km}$ in this phase. The graphical dependence of all the three phases of the smoke opacity value monitoring with utilization of tested substance in the observed vehicle no. 2 is shown in Fig. 2.

As evident from Fig. 4, the smoke opacity value after application of tested substance before decarbonization decreased by $55.1 \%$ in the first phase in comparison with the value specified by the manufacturer. When comparing the values before application of tested substance and before decarbonization in the first phase, the smoke opacity decreased by $11.5 \%$.

There was a decrease in smoke opacity by $43.5 \%$ in comparison with the smoke opacity value specified by manufacturer in the second phase (the process of decarbonization). In this phase, the mean smoke opacity value increased by $9.6 \%$ in comparison with the mean smoke opacity value before application of tested substance.

In the third phase (decarbonization process), the smoke opacity value decreased by $53.6 \%$ in comparison with the smoke opacity value specified by the manufacturer of vehicle no. 2 . When comparing the smoke opacity value before application of tested substance with the smoke opacity value after decarbonization in the third phase, smoke opacity decreased by $8.7 \%$.

Similarly, to the previous case, if only the first and third phases were included in the final assessment of the test sample's impacts on smoke opacity, then the mean smoke opacity value of vehicle no. 2 would be $0.93 \mathrm{~m}^{-1}$, representing a decrease in smoke opacity by $54.3 \%$ in comparison with the value specified by the manufacturer. When comparing the sums of mean smoke opacity values from the first and third phase before the application of tested substance, a $10.6 \%$ decrease in smoke opacity value is seen. 


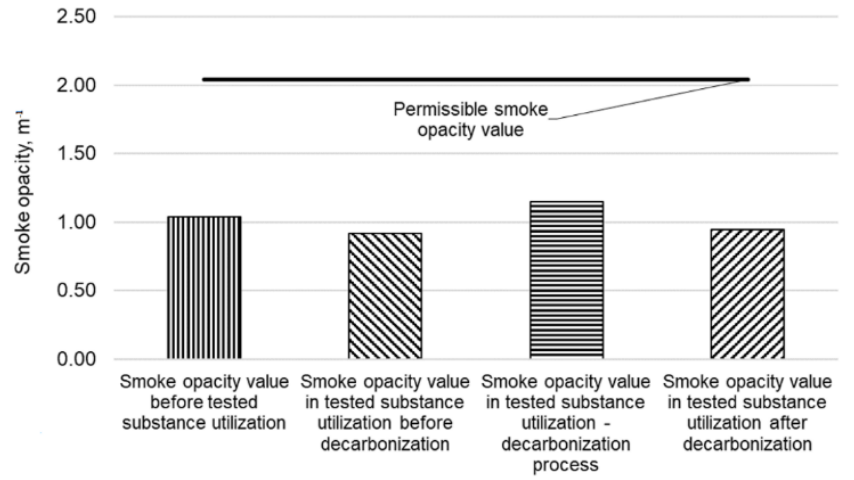

Fig. 2. Graphical dependence of individual smoke opacity monitoring phases using the test sample in the observed vehicle.

As already mentioned in the paper's introduction, one of the ways to meet the strict emission regulations is to focus attention on and search for suitable alternative fuels as a source of energy for compression ignition engines. Biodiesel fuel is the most utilized alternative fuel in compression ignition engines. The presented paper aims to point out other options for reduction of particulates in compression ignition engines by application of additives to the fuel system. The application of the tested substance resulted in a reduction of the smoke opacity value in both monitored vehicles by $14.25 \%$ on average. However, more significant reduction was observed for biodiesel. The reduction of particulate emissions in the range of 50-70\% in the testing of eight types of diesel fuel oil methylester fuels in the fuel system [19]. The next authors [20,21] also observed that the particulate emission values can be reduced by application of biodiesel to the fuel system. Authors [20], claim that it is possible to reduce particulate emissions by $75-91 \%$ by means of biofuel. Papers by [22, 23, 24, 25], who focused their research on monitoring of emissions from compression ignition engines, demonstrate that particulate emission values decreased by more than 50\%, in favor of biodiesel over diesel. Authors [26] also confirmed the reduction of particulate emissions by $20 \%$ and $50 \%$ at $20 \%$ and $100 \%$ biodiesel utilization. It is evident from the up-to-day results obtained in the compression ignition engine tests with biodiesel that smoke opacity is lower in comparison with the tested substance. However, it is necessary to emphasize that although biodiesel utilization results in reduction of smoke opacity, it also leads to a decrease in vehicle performance. Since neither the tests focused on monitoring of engine performance nor fuel consumption were performed in application of tested substance to the fuel system of compression ignition engine, further measuring and tests must be carried out within this area.

\section{Conclusions}

Nowadays, when our environment is overburdened with emissions of all kinds, every effort leading to reduction of the amount of harmful substances produced by combustion engines is of great significance. Emissions from compression ignition engines have negative impact on both the environment and people. This concerns especially the emissions of pollutants, namely "greenhouse" gases, which cause the gradual irreversible warming of the planet and disturb the balance in nature with acid rains. The major greenhouse gases are considered to be carbon dioxide $\mathrm{CO}_{2}$, oxides of nitrogen $\mathrm{NO}_{x}$, methane $\mathrm{CH}_{4}$ and oxides of sulfur $\mathrm{SO}_{\mathrm{x}}$.

The reduction of emissions, defined by regulations, can be achieved by two solutions in designing of motor vehicles. One solution is aimed at adjustment of combustion processes so that the minimum amount of monitored particulates are generated in the combustion chamber; the second solution is aimed at the so-called subsequent emission treatment in the 
exhaust pipe after emissions had been generated. The aforementioned solutions belong to groups of engine modifications and engine operating conditions.

Further efforts to reduce the environmental burden lead to the usage of alternative fuels applied in positive ignition and compression ignition engines, hybrid drives and electric generators.

The obtained results presented in this paper demonstrate that the tested substance, which was applied to the vehicle tank in the set mixing ratio resulted in reduction of smoke opacity by $18.0 \%$ in vehicle no. 1 . The smoke opacity in vehicle no. 2 was reduced by $10.2 \%$. The minimum number of measurements -67 - was determined on the basis of mathematical and statistical analysis and was respected for both vehicles during the tests. The mileage of vehicle no. 1 was $15,560 \mathrm{~km}$. The mileage of vehicle no. 2 was $14,440 \mathrm{~km}$. In both tested vehicles, an increase in smoke opacity value occurred in a certain phase of monitoring. This is a result of the tested substance impacts - it decarbonizes the combustion chamber and thus maintains fuel system cleanliness. Decarbonization was realized at different intervals in the vehicles, which can be a result of different mileages, as well as different vehicle loads.

This work was supported by AgroBioTech Research Centre built in accordance with the project Building „AgroBioTech" Research Centre ITMS 26220220180.

Project VEGA 1/0464/17 "Monitoring of the impact of ecological fuels obtained from agricultural production and additives in hydrocarbon fuels to technical and environmental performance of internal combustion engines used in agricultural and transport machines"

Project VEGA 1/0155/18 „Applied research of the use of ecological energy carriers in agricultural, forestry and transport technology.“

Pproject APVV SK-PL-18-0041 „The development of scientific cooperation in the study of the effect of biofuels in road transport, including environmental impact."

\section{References}

1. P. Lend’ák, J. Jablonický, D. Uhrinová, J. Kosiba, J. Polerecký, $A M R$, vol 1059, pp. 119-125, (2014)

2. J. Jablonický, Z. Tkáč, M. Majdan, D. Uhrinová, L. Hujo, V. Vozárová. 2012 Properties evaluation of biofuels and bio-lubricants (Press Slovak University of Agriculture in Nitra, Nitra, 2012)

3. M. Králik, J. Jablonický, M. I. Nikolov, Monitoring of NOx emissions at selected diesel engine (Angel Kanchev University of Ruse, Ruse, 2015)

4. J. Čedík, M. Pexa, B. Peterka, M. Holubek, D. Mader, R. Pražan, ATA, 21(4) (2018), pp. $130-135$

5. I. Janoško, P. Kuchar, Agron. Res., 16(3) (2018), pp. 737-748

6. P. Dostál, J. Rozlivka, V. Kumbár, 2019. ATA, (22) 1, (2019) pp. 17-21

7. J. Čupera, P. Štěrba, 2010. Diagnosis of motor vehicles I. (Avid s.r.o. Brno, 2010)

8. N. V. Heeb, M. Zennegg, R. Haag, C. Seiler, P. Schmid, A. Wichser, A. Ulrich, P. Honegger, K. Zeyer, L. Emmeneggerer, Y. Zimmerli, J. Czerwinski M. Kasper, M. Mayer, In Conference Proc. 15th ETH Conference on Combustion Generated Nanoparticles. Zurich; Switzerland, Poster (2011)

9. F. Vlk F. Automotive combustion engines (VLK, Brno, 2003)

10. Y. Ulusoy, R. Arslan, C. Kaplan, Energy Sources, 31(11) (2009), pp. 906-910

11. G. P. Hammond, S. Kallu, M. C. McManus, Appl. Energy 85(6) (2018), pp. 506-515.

12. Regulation no. 24 of the Economic Commission for Europe of the United Nations (UN/ECE). Uniform provisions concerning: I. The approval of compression ignition (C.I.) engines with regard to the emission of visible pollutants; II. The approval of motor vehicles with regard to the installation of C.I. engines of an approved type; III. 
The approval of motor vehicles equipped with C.I. engines with regard to the emission of visible pollutants by the engine; IV. The measurement of power of C.I. engines

13. M. P. Dorado, E. Ballesteros, J. M. Arnal, J. Gómez, F. J. López, Fuel 82(11), (2003), pp. 1311-1315

14. Regulation no. 49 of the Economic Commission for Europe of the United Nations (UN/ECE). Emissions of C.I. and P.I. (NG and LPG) engines

15. Directive 2014/45/EU of the European Parliament and of the Council of 3 April 2014 on periodic roadworthiness tests for motor vehicles and their trailers and repealing Directive 2009/40/EC Text with EEA relevance

16. Law no. 106/ 2018 of 14 March 2018 on the operation of vehicles in road traffic and on the amendment of certain laws

17. ISO 11614:1999, (1999)

18. V. Rataj, Preparing a scientific and professional text, (SUA in Nitra, pp. 171, 2003)

19. B. F. Lin, J. H. Huang, D. Y. Huang, Fuel 88(9) (2009), pp. 1779-1785

20. N. Y. Kado, P. A. Kuzmicky, National Renewable Energy Laboratory, p. 26. NREL/SR-510-31463, (2003)

21. J. Čedík, M. Pexa, B. Peterka, M. Holubek, D. Mader, R. Pražan, 2018. Agron. Res. 16 (S1) (2018), pp. 985-996

22. S. Puhan, N. Vedaraman, N., Sankaranarayanan, B. V. Bharat, Ram, Renew. Energy 30(8) (2005), pp. 1269-1278

23. A. N. Ozsezen, M. Canakci, A. Turkcan, C. Sayin, Fuel 88(4) (2009), pp. 629-636

24. P. K. Sahoo, L. M. Das, M. K. Babu, P. Arora, V. P. Singh, N. R. Kumar, T. S. Varyni, Fuel 88(9) (2009), pp. 1698-1707

25. J. M. Luján, V. Bermúdez, B. Tormos, B. Pla, Biomass Bioenerg. 33(6-7) (2009), pp. 948-956

26. M. J. Haas, K. M. Scott, T. L. Alleman, R. L. McCormick, Energ. Fuel, 15(5) (2001), pp. 1207-1212 